\title{
CORRIGENDUM
}

\section{The reproducibility of subjective appetite scores}

BY ANNE RABEN, ANNA TAGLIABUE AND ARNE ASTRUP

Vol. 73 (1995), no. 4

Page 520

For $\quad C V=\frac{\sqrt{\frac{\text { (difference) }^{2}}{2 \times \text { number of pairs }}}}{\text { mean }}$.

Read $\quad \mathrm{CV}(\%)=\frac{\sqrt{\frac{\sum_{i=1}^{n}(\text { difference })^{2}}{2 \times \text { number of pairs }}}}{\text { mean }} \times 100$. 